\title{
Low-flow $\mathrm{CO}_{2}$ removal in combination with renal replacement therapy effectively reduces ventilation requirements in hypercapnic patients: a pilot study
}

\author{
Jens Nentwich ${ }^{1}$, Dominic Wichmann², Stefan Kluge ${ }^{2}$, Simone Lindau ${ }^{3}$, Haitham Mutlak ${ }^{3}$ and Stefan John ${ }^{*}$
}

\begin{abstract}
Background: Lung-protective strategies are the cornerstone of mechanical ventilation in critically ill patients with both $\mathrm{ARDS}$ and other disorders. Extracorporeal $\mathrm{CO}_{2}$ removal $\left(\mathrm{ECCO}_{2} \mathrm{R}\right)$ may enhance lung protection by allowing even further reductions in tidal volumes and is effective in low-flow settings commonly used for renal replacement therapy. In this study, we describe for the first time the effects of a labeled and certified system combining $\mathrm{ECCO}_{2} \mathrm{R}$ and renal replacement therapy on pulmonary stress and strain in hypercapnic patients with renal failure.

Methods: Twenty patients were treated with the combined system which incorporates a membrane lung $\left(0.32 \mathrm{~m}^{2}\right)$ in a conventional renal replacement circuit. After changes in blood gases under $\mathrm{ECCO}_{2} \mathrm{R}$ were recorded, baseline hypercapnia was reestablished and the impact on ventilation parameters such as tidal volume and driving pressure was recorded.

Results: The system delivered $\mathrm{ECCO}_{2} \mathrm{R}$ at rate of $43.4 \pm 14.1 \mathrm{ml} / \mathrm{min}, \mathrm{PaCO}_{2}$ decreased from $68.3 \pm 11.8$ to $61.8 \pm 11.5 \mathrm{mmHg}(p<0.05)$ and $\mathrm{pH}$ increased from $7.18 \pm 0.09$ to $7.22 \pm 0.08(p<0.05)$. There was a significant reduction in ventilation requirements with a decrease in tidal volume from $6.2 \pm 0.9$ to $5.4 \pm 1.1 \mathrm{ml} / \mathrm{kg}$ PBW $(p<0.05)$ corresponding to a decrease in plateau pressure from $30.6 \pm 4.6$ to $27.7 \pm 4.1 \mathrm{cmH}_{2} \mathrm{O}(p<0.05)$ and a decrease in driving pressure from $18.3 \pm 4.3$ to $15.6 \pm 3.9 \mathrm{cmH}_{2} \mathrm{O}(p<0.05)$, indicating reduced pulmonary stress and strain. No complications related to the procedure were observed.
\end{abstract}

Conclusions: The investigated low-flow $\mathrm{ECCO}_{2} \mathrm{R}$ and renal replacement system can ameliorate respiratory acidosis and decrease ventilation requirements in hypercapnic patients with concomitant renal failure.

Trial registration NCT02590575, registered 10/23/2015.

Keywords: Low-flow extracorporeal $\mathrm{CO}_{2}$ removal, Mechanical ventilation, Lung protection, Ventilator-induced lung injury, Acute kidney injury, Renal replacement therapy, Multi-organ support

\footnotetext{
*Correspondence: stefan.john@klinikum-nuernberg.de

${ }^{1}$ Medical Intensive Care, Department of Cardiology, Klinikum Nuremberg,

Paracelsus Medical University, Nuremberg, Germany

Full list of author information is available at the end of the article
} 


\section{Background}

Lung-protective strategies are the mainstay of mechanical ventilation in patients with ARDS and other inflammatory pulmonary disorders, as the use of lower tidal volumes and plateau pressures improves survival rates by reducing pulmonary stress and strain $[1,2]$. In addition, there is a growing body of evidence that a further reduction in the mechanical stress resulting from positive pressure ventilation by further decreasing tidal volumes may be even more "lung protective" [3-5]. Whereas low tidal volume ventilation has been shown to reduce pulmonary inflammation and consequently mortality, it is often accompanied by hypercapnic acidosis, which will even be more pronounced under "ultra-protective" ventilation strategies. Although elevated $\mathrm{PaCO}_{2}$ levels in this setting ("permissive hypercapnia") are often well tolerated and deemed to be safe [1-3], the degree to which hypercapnia may be tolerable or even beneficial by directly supporting anti-inflammation remains unclear [6-9]. Very recent data have shown a positive correlation between hypercapnic acidosis and mortality $[10,11]$, thereby casting doubt on the uncritical toleration of hypercapnic acidosis under lung-protective mechanical ventilation. On the other hand, many patients with ARDS present with multi-organ failure, e.g., due to septic shock, and consequently exhibit massive metabolic acidosis in combination with severe cardiovascular instability. This may further limit the concept of permissive hypercapnia since an additional decrease in $\mathrm{pH}$ may be considered unsafe in such patients. This problem is even more pronounced when aiming for an additional reduction in the invasiveness of mechanical ventilation by further reducing tidal volumes.

Although there are no conclusive data showing a reduction in mortality, there is evidence that extracorporeal $\mathrm{CO}_{2}$ removal $\left(\mathrm{ECCO}_{2} \mathrm{R}\right)$ can effectively normalize severe hypercapnia and facilitate ultra-protective ventilation strategies [12-15]. Whereas extracorporeal membrane oxygenation (ECMO) is becoming more and more widespread in the therapy of patients with severe ARDS and provides total decarboxylation in addition to oxygenation, such high-flow systems require substantial resources and carry a considerable risk of complications and are therefore limited to patients with severe hypoxemia [16-22]. Total extracorporeal $\mathrm{CO}_{2}$ removal can be achieved with less invasive techniques such as pumpless extracorporeal lung assist (pECLA) and other mid-flow systems [23, 24], but these techniques still require specialized vascular access and are therefore invasive and expensive.

On the other hand, it has repeatedly been demonstrated that even low-flow systems adapted from conventional renal replacement platforms with blood flow rates under $500 \mathrm{ml} / \mathrm{min}$ can achieve significant $\mathrm{CO}_{2}$ elimination ("respiratory dialysis") [25-27]. Extracorporeal $\mathrm{CO}_{2}$ removal based on renal replacement platforms may be especially useful in mechanically ventilated patients with multi-organ failure, since in one- to two-thirds of those patients there is an indication for renal replacement therapy [28, 29]. Furthermore, concomitant lung and kidney injury may exhibit significant detrimental interaction ("organ cross talk") [30, 31], which may negatively affect outcome. Because no additional vascular access other than the dialysis catheter is required, the implementation of a hollow-fiber gas exchanger in the renal replacement circuit could be an attractive therapeutic option in such patients.

Though the use of such combinations of $\mathrm{ECCO}_{2} \mathrm{R}$ and continuous renal replacement therapy (CRRT) has been reported [27, 32, 33], until recently no certified combination therapy has been available. In this pilot study, we describe for the first time the effectiveness of a commercially available combination of $\mathrm{ECCO}_{2} \mathrm{R}$ and CRRT regarding decarboxylation and ventilation as well as other clinical parameters.

\section{Methods}

\section{Aims of the study, inclusion and exclusion criteria}

The main goals of this multicenter observational pilot study were (1) to determine the changes in blood gases under the combined renal replacement and decarboxylation therapy and (2) to record the reduction in plateau pressures and tidal volumes that can thus be achieved. Secondary measurements included changes in ventilator settings, systemic hemodynamics, membrane lung performance, running time and patency of the extracorporeal circuit as well as documentation of system-related complications. The study protocol was approved by the local ethics committees at all three participating centers. We aimed to analyze data from 20 critically ill patients with the following inclusion criteria: (1) mechanical ventilation according to ARDS Network criteria with a prospected duration of at least $24 \mathrm{~h},(2)$ hypercapnic acidosis with a $\mathrm{pH}$ below 7.30 and a $\mathrm{PaCO}_{2}$ of at least $55 \mathrm{mmHg}$ under a plateau pressure of at least $25 \mathrm{cmH}_{2} \mathrm{O}$ and (3) indication for renal replacement therapy. The study was registered under NCT02590575.

\section{Extracorporeal circuit}

The Prismalung ${ }^{\mathrm{TM}}$ system (Baxter Gambro Renal, USA) consists of a $0.32-\mathrm{m}^{2}$ membrane oxygenator that can be included in the Prismaflex ${ }^{\mathrm{TM}}$ organ support platform either in a stand-alone fashion or in combination with CRRT to provide low-flow $\mathrm{CO}_{2}$ removal. For this study, we utilized the combination therapy where the membrane oxygenator is inserted serially in the extracorporeal 
circuit downstream to the hemofilter. $100 \%$ oxygen was used as sweep gas. The Prismaflex ${ }^{\mathrm{TM}}$ system is equipped with a software extension; otherwise, there are no changes compared to the basic CRRT mode. Systemic anticoagulation with unfractioned heparin and a target aPTT (activated partial thromboplastin time) of $60 \mathrm{~s}$ was used to prevent clotting in the extracorporeal circuit. Temperature management was according to local practice standards using tube heating or optionally a conventional heat exchanger directly connected to the membrane oxygenator. Renal replacement therapy was provided according to local practice standards as continuous veno-venous hemofiltration (CVVHF) using bicarbonate-buffered replacement fluids. CRRT dose was calculated according to international guideline recommendations; approximately one-third of the dose was applied as pre-dilution.

\section{Study protocol}

Patients underwent a checklist-based screening for inclusion criteria. If inclusion criteria were met and no exclusion criteria were present, informed consent was obtained by the patient or legal guardian. After inclusion patients underwent a 2-h stabilization period to ensure stable cardiovascular and respiratory conditions before implementation of the extracorporeal circuit. Adequate analgosedation with a Richmond agitation and sedation scale (RASS) target of -4 was provided, neuromuscular blockade was not mandatory. During this period, vascular access was obtained with a conventional 13.5 French Shaldon catheter (Bard Access Systems, USA) via an internal jugular ( $75 \%$ of patients, catheter length $20 \mathrm{~cm}$ ) or femoral vein ( $25 \%$ of patients, catheter length $24 \mathrm{~cm}$ ) and the system was primed. The stabilization period could be shortened if the immediate commencement of renal replacement therapy was deemed to be necessary. After connecting the patient to the circuit and before starting sweep gas flow, baseline parameters were collected. Then sweep gas was started at a flow rate of $8 \mathrm{l} /$ min and remained unchanged throughout the study. After recording changes in blood gases after a running time of $30 \mathrm{~min}$, ventilator settings were adapted (i.e., $P_{\text {plat }}$ lowered) with the goal of reestablishing baseline $\mathrm{PaCO}_{2}$. Original $\mathrm{PaCO}_{2}$ was reinstated using end-tidal $\mathrm{CO}_{2}$ as guidance and confirmed through blood gas analysis. After another $30 \mathrm{~min}$ data were collected and again at 24,48 and $72 \mathrm{~h}$ after implementation. Ventilator settings were left to the discretion of the treating physician as soon as the initial data collections (at 30 and $60 \mathrm{~min}$ ) were completed. The study ended after $72 \mathrm{~h}$ or loss of the system due to clotting. In case of system loss within the first $24 \mathrm{~h}$, a new system could be implemented and data collection continued.

\section{Statistical analysis and $\mathrm{ECCO}_{2} \mathrm{R}$ calculation}

Data were collected using paper-based case record forms, and a database was created with conventional spreadsheet software (Microsoft Excel 2010). Mean and median values as well as standard deviations were calculated and one-sided Student's $t$ test was used for statistical comparison assuming normally distributed data. Diagrams were created with SciDAVis open-source software (version 1.22). Blood gas analysis was performed using a conventional blood gas analyzer (ABL 800 Flex, Radiometer, Denmark), and $\mathrm{ECCO}_{2} \mathrm{R}$ rate was calculated from blood flow and the difference between blood $\mathrm{CO}_{2}$ content at the beginning and end of the extracorporeal circuit according to the following equation [34]:

$\mathrm{CO}_{2}$ removal rate $=\left(\mathrm{CO}_{2}\right.$ arterial content$\mathrm{CO}_{2}$ venous content $) \times$ blood flow $=24 \times\left(\left(\mathrm{HCO}_{3}\right.\right.$ arterial $+0.03 \times \mathrm{PCO}_{2} \quad$ arterial $)-\left(\mathrm{HCO}_{3}\right.$ venous $+0.03 \times \mathrm{PCO}_{2}$ venous) $) \times$ blood flow with arterial and venous referring to the arterial and venous lines of the extracorporeal circuit, respectively.

\section{Results}

\section{Patient characteristics}

Between January 2016 and February 2017, 26 critically ill patients in three centers were included in the study. Because of the wrong application of inclusion criteria and inconsistent baseline measurements, data of 20 patients were included in the final analysis. All patients were on pressure-controlled mechanical ventilator support, received an opiate-based analgosedation regime and were on vasopressor support. The leading indications for renal replacement therapy were sepsis in $9 / 20$ patients and established chronic renal failure in $6 / 20$ patients; other indications included shock and acute cardiorenal syndrome. One surgical patient was included; all other patients $(19 / 20)$ were medical. Patient characteristics and parameters at inclusion are given in Tables 1 and 2, respectively.

\section{$\mathrm{ECCO}_{2} \mathrm{R}$, blood gases and $\mathrm{CO}_{2}$ transfer}

The average overall $\mathrm{ECCO}_{2} \mathrm{R}$ rate of the combined system was $43.4 \pm 14.1 \mathrm{ml} / \mathrm{min}$ with a maximum of $75.0 \mathrm{ml} / \mathrm{min}$ and remained above $40 \mathrm{ml} / \mathrm{min}$ during the course of the study (Fig. 1). The $\mathrm{CO}_{2}$ elimination rate of the membrane lung alone was slightly higher $(45.4 \pm 15.7 \mathrm{ml} / \mathrm{min})$. The resulting decrease in the $\mathrm{CO}_{2}$ content of extracorporeal blood was $113 \mathrm{ml} / \mathrm{l}(640 \pm 98$ vs. $527 \pm 103 p<0.05)$ corresponding to a decrease in patient arterial $\mathrm{CO}_{2}$ of $6.5 \mathrm{mmHg}(68.3 \pm 11.8$ vs. $61.8 \pm 11.5, p<0.05)$ and an increase in $\mathrm{pH}$ from $7.18 \pm 0.09$ to $7.22 \pm 0.08(p<0.05)$ after $30 \mathrm{~min}$ (Table 3 ). No change in systemic oxygenation was observed at this point. During the remaining 


\section{Table 1 Patient characteristics}

\begin{tabular}{ll}
\hline Age (years) & $\mathbf{6 4}(\mathbf{4 3 - 8 2 )}$ \\
\hline Male sex & $12 / 20(60 \%)$ \\
BMI $\left(\mathrm{kg} / \mathrm{m}^{2}\right)$ & $29.4(24.2-39.7)$ \\
SAPS II & $57(27-79)$ \\
Patient category & \\
Medical & $19 / 20(95 \%)$ \\
Surgical & $1 / 20(5 \%)$ \\
SOFA & $14(8-18)$ \\
Main diagnoses & \\
Pneumonia & $17 / 20(85 \%)$ \\
Septic shock & $14 / 20(70 \%)$ \\
ARDS & $8 / 20(40 \%)$ \\
COPD & $7 / 20(35 \%)$ \\
CIHD & $6 / 20(30 \%)$ \\
Analgosedation & \\
Opiates & $20 / 20(100 \%)$ \\
Sedation & $19 / 20(95 \%)$ \\
NMBA & $5 / 20(25 \%)$ \\
Hemodynamic support & \\
Vasopressors & $20 / 20(100 \%)$ \\
Inotropes & $2 / 20(10 \%)$ \\
\hline
\end{tabular}

BMI body mass index; SAPS Simplified Acute Physiology Score; SOFA Sequential Organ Failure Assessment; ARDS acute respiratory distress syndrome; COPD chronic obstructive pulmonary disease; $C I H D$ chronic intermittent hemodialysis; $N M B A$ neuromuscular blocking agent

Table 2 Parameters at inclusion

\begin{tabular}{|c|c|c|}
\hline Parameter & Value $\pm S D$ & Range \\
\hline $\mathrm{pH}$ & $7.20 \pm 0.08$ & $7.02-7.31$ \\
\hline $\mathrm{PaCO}_{2}(\mathrm{mmHg})$ & $66.3 \pm 8.7$ & $56.1-84.4$ \\
\hline $\mathrm{HCO}_{3}(\mathrm{mmol} / \mathrm{l})$ & $24.1 \pm 3.9$ & $17.1-34.3$ \\
\hline $\mathrm{CaCO}_{2}(\mathrm{ml} / \mathrm{l})$ & $626 \pm 93$ & $457-881$ \\
\hline $\mathrm{SBE}(\mathrm{mmol} / \mathrm{l})$ & $-2.4 \pm 4.8$ & $-11.7-11.9$ \\
\hline $\mathrm{SaO}_{2}(\%)$ & $95 \pm 2$ & 88-98 \\
\hline$P / F(\mathrm{mmHg})$ & $159 \pm 36$ & $107-224$ \\
\hline$V_{T} / \mathrm{PBW}(\mathrm{ml} / \mathrm{kg})$ & $6.0 \pm 0.7$ & $4.5-7.9$ \\
\hline $\mathrm{RR}(\mathrm{bpm})$ & $25 \pm 4$ & $16-31$ \\
\hline RMV (I/min) & $9.6 \pm 1.7$ & $6.3-12.7$ \\
\hline$P_{\text {plat }}\left(\mathrm{cmH}_{2} \mathrm{O}\right)$ & $30 \pm 4$ & $25-38$ \\
\hline $\operatorname{PEEP}\left(\mathrm{cmH}_{2} \mathrm{O}\right)$ & $12 \pm 3$ & $6-18$ \\
\hline$\Delta \mathrm{P}\left(\mathrm{cmH}_{2} \mathrm{O}\right)$ & $18 \pm 4$ & $11-26$ \\
\hline $\mathrm{C}_{\text {dyn }}\left(\mathrm{ml} / \mathrm{cmH}_{2} \mathrm{O}\right)$ & $27.5 \pm 10.8$ & $14.9-48.0$ \\
\hline $\mathrm{HR}(\mathrm{bpm})$ & $101 \pm 20$ & $70-150$ \\
\hline $\mathrm{MAP}(\mathrm{mmHg})$ & $72 \pm 12$ & $56-98$ \\
\hline Norepinephrine dose (mg/h] & $2.7 \pm 2.2$ & $0.4-9.0$ \\
\hline RASS & $-4 \pm 1$ & -5 to -3 \\
\hline
\end{tabular}

$\mathrm{PaCO}_{2}$ arterial $\mathrm{CO}_{2}$ partial pressure; $\mathrm{HCO}_{3}$ bicarbonate concentration; $\mathrm{CaCO}_{2}$ arterial $\mathrm{CO}_{2}$ content; $\mathrm{SBE}$ standard base excess; $\mathrm{SaO}_{2}$ arterial $\mathrm{O}_{2}$ saturation; $\mathrm{P} / \mathrm{F}$ oxygenation index; $V_{\mathrm{T}}$ tidal volume; $P B W$ predicted body weight; $R R$ respiratory rate; $R M V$ respiratory minute volume; $P_{\text {plat }}$ plateau pressure; $P E E P$ positive endexpiratory pressure; $\Delta P$ driving pressure; $C_{\text {dyn }}$ dynamical compliance; $H R$ heart rate; MAP mean arterial pressure; RASS Richmond agitation and sedation scale study period, a further normalization of blood gases was observed (Fig. 2). Passage of the membrane lung reduced extracorporeal blood $\mathrm{CO}_{2}$ content from $645 \pm 94$ to $527 \pm 103 \mathrm{ml} / \mathrm{l}(-18 \%)$, corresponding to a drop in $\mathrm{PCO}_{2}$ from $66.6 \pm 12.6$ to $32.3 \pm 5.5 \mathrm{mmHg}(-52 \%)$.

\section{Ventilation}

After ventilator settings were adapted and baseline $\mathrm{PaCO}_{2}$ was reestablished, we recorded a decrease in respiratory minute ventilation from $9.9 \pm 2.1$ to $8.5 \pm 2.1 \mathrm{l} /$ $\min (-1.4 \mathrm{l} / \mathrm{min}, p<0.05)$, corresponding to a reduction in tidal volume from $6.2 \pm 0.9$ to $5.4 \pm 1.1 \mathrm{ml} / \mathrm{kg}$ of predicted body weight (PBW) $(-0.8 \mathrm{ml} / \mathrm{kg}, p<0.05)$. Plateau pressures decreased from $30.6 \pm 4.6$ to $27.7 \pm 4.1 \mathrm{cmH}_{2} \mathrm{O}$ $\left(-2.9 \mathrm{cmH}_{2} \mathrm{O}, p<0.05\right)$ and driving pressures from $18.3 \pm 4.3$ to $15.6 \pm 3.9 \mathrm{cmH}_{2} \mathrm{O}\left(-2.7 \mathrm{cmH}_{2} \mathrm{O}, p<0.05\right)$, respectively (Table 4$)$. Ventilatory parameters showed a trend toward baseline values over the remaining study period (Fig. 3). After reduction in ventilator settings, a lower $\mathrm{PaO}_{2}(91.8 \pm 23.8$ vs. $84.4 \pm 18.7 \mathrm{mmHg}, p<0.05)$ corresponding to a lower oxygenation index $(164 \pm 38 \mathrm{vs.}$ $151 \pm 35 \mathrm{mmHg}, p<0.05$ ) was observed (Table 4).

\section{Extracorporeal circuit}

Out of 20 patients, 16 (80\%) completed the 72-h study period. The total running time of the system was $95.8 \pm 47.7 \mathrm{~h}$ (range 14.5 to $223.4 \mathrm{~h}$ ). Altogether five systems were lost due to clotting, three of which were replaced and the study continued. There were no interruptions of the therapy due to patient transport. The average activated partial thromboplastin time (aPTT) was $62 \pm 16 \mathrm{~s}$ after $24 \mathrm{~h}, 57 \pm 19 \mathrm{~s}$ after $48 \mathrm{~h}$ and $59 \pm 20 \mathrm{~s}$ after $72 \mathrm{~h}$ at an average continuous dose of unfractioned heparin of $1154 \pm 556 \mathrm{IU} / \mathrm{h}$, which corresponds to two times the reference range (25-34 s). The targeted blood flow rate of $400 \mathrm{ml} / \mathrm{min}$ was reached in $17 / 20$ patients (85\%). In the majority of patients $(12 / 20)$, vascular access was via a jugular Shaldon catheter, whereas a femoral catheter was used in the remaining patients. In two out of three patients in whom the targeted blood flow rate could not be reached, vascular access was via a left jugular Shaldon catheter which was consequently changed. The recorded pressures in the arterial and venous line of the circuit were $-148 \pm 27 \mathrm{mmHg}$ and $164 \pm 36 \mathrm{mmHg}$, respectively. Transmembranous pressures in the hemofilter increased continually over time from $46 \pm 22 \mathrm{mmHg}$ at baseline to $76 \pm 21 \mathrm{mmHg}$ at $72 \mathrm{~h}$, whereas oxygenation performance of the membrane lung $\left(\Delta \mathrm{PO}_{2}\right)$ decreased from $350 \pm 62$ to $311 \pm 63 \mathrm{mmHg}$. Renal replacement was effected by conventional hemofiltration (CVVHF) using bicarbonate-buffered replacement fluids with an average dose of $2615 \pm 470 \mathrm{ml} / \mathrm{h}$ of total effluent. Renal parameters as well as phosphate levels developed 


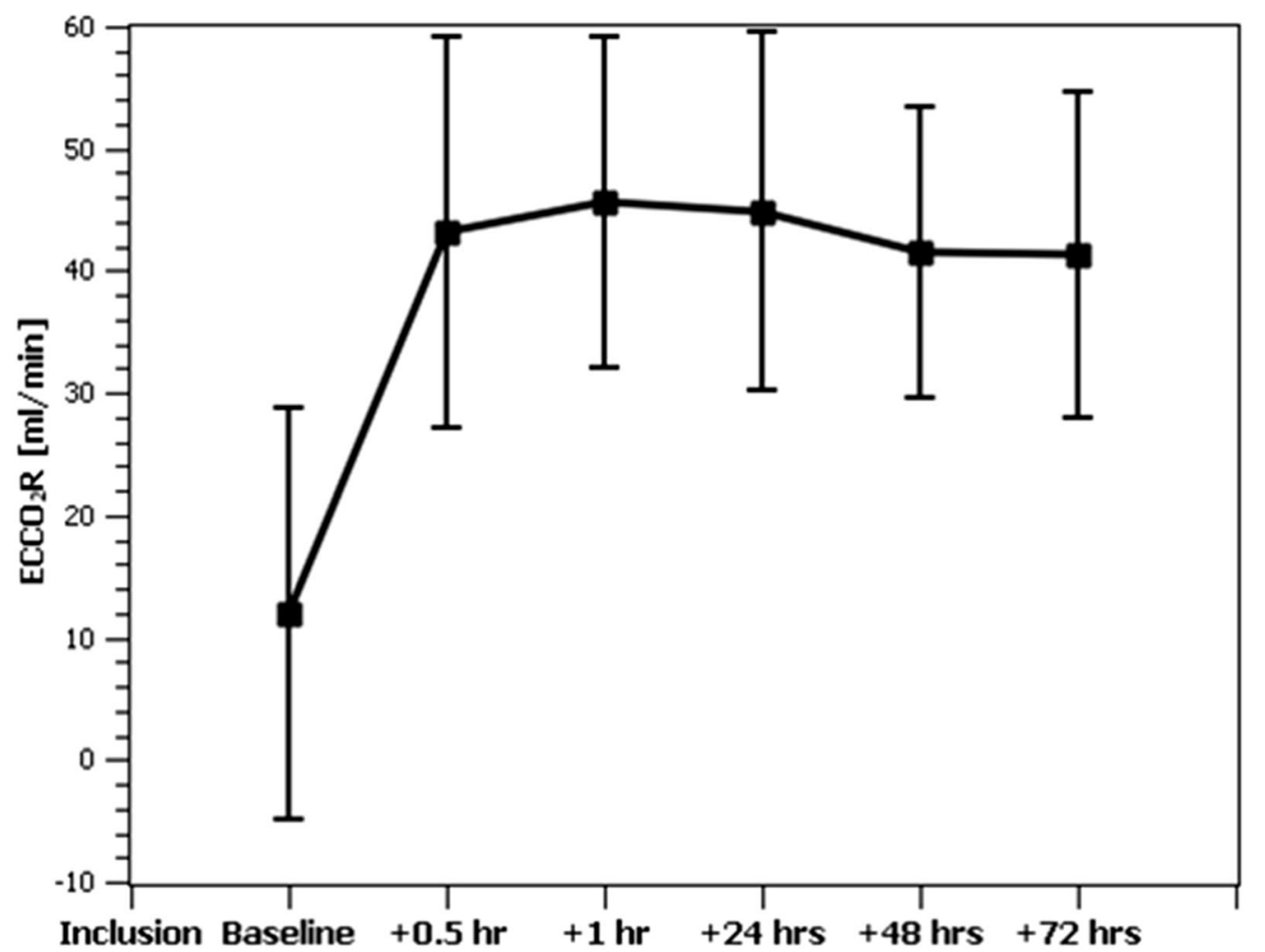

Fig. 1 Time course of $\mathrm{ECCO}_{2} \mathrm{R}$ over the study period. At baseline, the patient was connected to the extracorporeal circuit with the sweep gas flow over the membrane lung turned off

Table 3 Changes in arterial $\mathrm{CO}_{2}$ load, partial pressure and $\mathrm{pH}$ between baseline and at $0.5 \mathrm{~h}$

\begin{tabular}{lllll}
\hline & Baseline & $\mathbf{+ 0 . 5} \mathbf{h}$ & $\boldsymbol{\Delta}(\%)$ & $\boldsymbol{P}$-value \\
\hline $\mathrm{pH}$ & $7.18 \pm 0.09$ & $7.22 \pm 0.08$ & +0.04 & $<0.05$ \\
$\mathrm{PaCO}_{2}(\mathrm{mmHg})$ & $68.3 \pm 11.8$ & $61.8 \pm 11.5$ & $-6.5(-9.5)$ & $<0.05$ \\
$\mathrm{CaCO}_{2}(\mathrm{ml} / \mathrm{l})$ & $623 \pm 106$ & $611 \pm 98$ & $-12(-1.9)$ & $<0.05$ \\
\hline
\end{tabular}

$\mathrm{PaCO}_{2}$ arterial $\mathrm{CO}_{2}$ partial pressure; $\mathrm{CaCO}_{2}$ arterial $\mathrm{CO}_{2}$ content

as expected, which resulted in a significant decrease in plasma creatinine $(3.30 \pm 2.59$ vs. $1.42 \pm 0.42 \mathrm{mg} / \mathrm{dl})$ and urea $(72 \pm 50$ vs. $31 \pm 18 \mathrm{mg} / \mathrm{dl})$ over the study period. Serum bicarbonate did not depart significantly from baseline values. A slight decrease in average thrombocyte count compared to baseline was observed after $24 \mathrm{~h}$ $\left(164 \pm 75\right.$ vs. $\left.184 \pm 89 \mathrm{nl}^{-1}\right)$, and thrombocytes reached baseline levels after $72 \mathrm{~h}\left(179 \pm 94 \mathrm{nl}^{-1}\right)$.

\section{Systemic hemodynamics}

No adverse cardiovascular effects were observed following implementation of the extracorporeal circuit. Two patients died within $24 \mathrm{~h}$ after inclusion due to refractory septic shock. In the remaining patients, hemodynamic improvement with markedly reduced vasopressor requirements (norepinephrine dose $3.1 \pm 2.9$ vs. $2.4 \pm 2.0 \mathrm{mg} / \mathrm{h}, p<0.05)$ and heart rate $(103 \pm 18$ vs. $91 \pm 23 \mathrm{bpm}, p<0.05)$ was recorded after $24 \mathrm{~h}$. Hemodynamics remained stable over the further study period.

\section{Complications}

Four patients received blood products during the study; altogether 11 units of packed red blood cells (RBC) and one unit of thrombocytes were transfused. The major part of those blood products (eight units of packed RBC and one unit of thrombocytes) was given to two patients who had previously undergone allogeneic stem cell transplantation, thus confounding transfusion requirements. No bleeding directly attributed to the extracorporeal circuit was reported and no other clinical relevant hematological abnormalities such as signs of hemolysis or hyperfibrinolysis were detected during the course of the study. No other adverse effects were reported. 

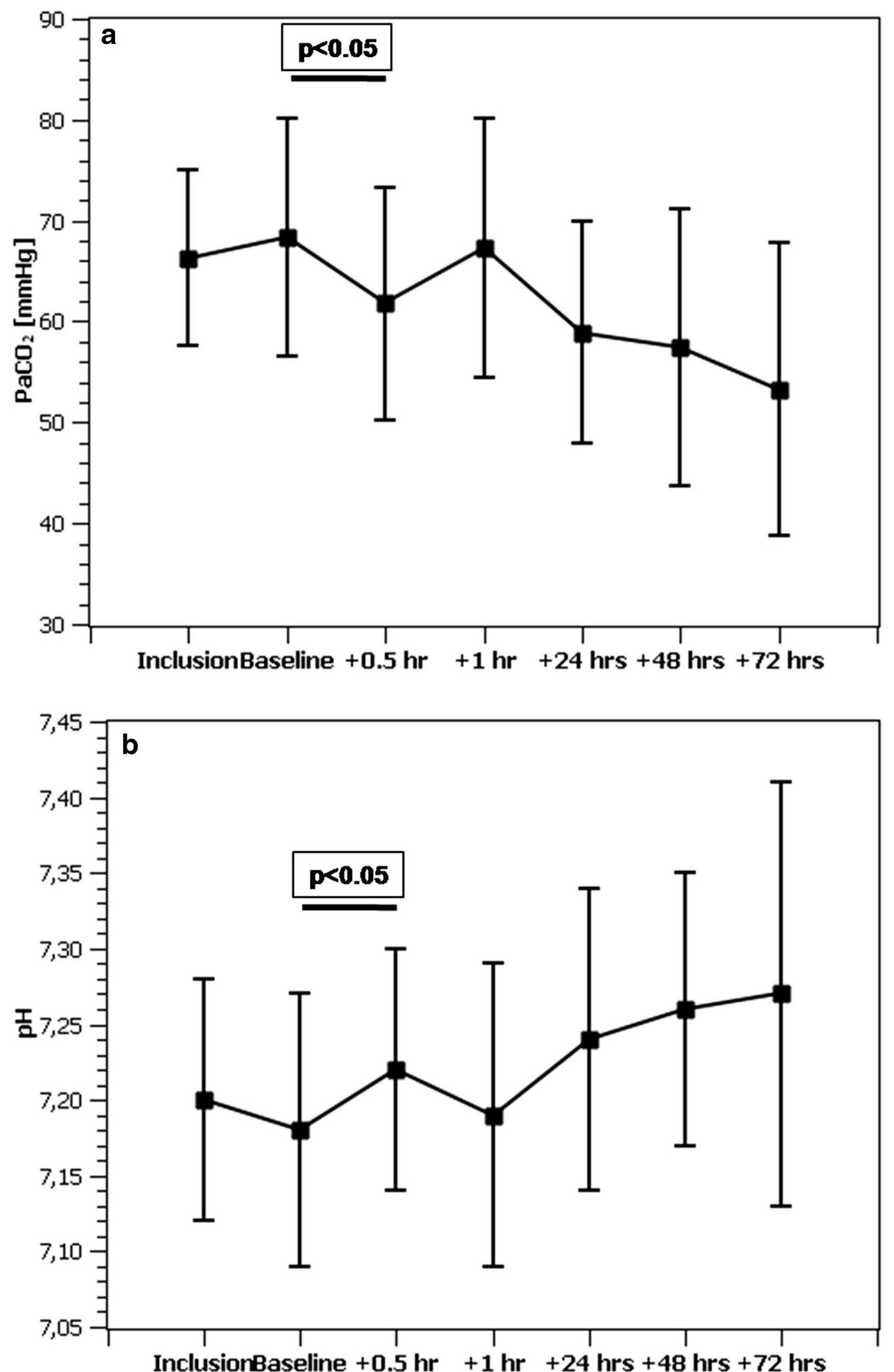

Fig. 2 Time course of $\mathbf{a}$ arterial $\mathrm{CO}_{2}$ partial pressure and $\mathbf{b} \mathrm{pH}$ over the study period. After adjusting ventilation parameters to reestablish baseline $\mathrm{PaCO}_{2}$ at $1 \mathrm{~h}$, a trend toward further normalization of hypercapnic acidosis was observed 
Table 4 Changes in ventilation and oxygenation parameters between baseline and after reduction in tidal volumes at $1 \mathrm{~h}$

\begin{tabular}{lccll}
\hline & Baseline & $\mathbf{+ 1} \mathbf{h}$ & $\boldsymbol{\Delta}(\%)$ & $\boldsymbol{P}$-value \\
\hline$V_{\mathrm{T}} / \mathrm{PBW}(\mathrm{ml} / \mathrm{kg})$ & $6.2 \pm 0.9$ & $5.4 \pm 1.1$ & $-0.8(-12.9)$ & $<0.05$ \\
$\mathrm{RMV}(\mathrm{I} / \mathrm{min})$ & $9.9 \pm 2.1$ & $8.5 \pm 2.1$ & $-1.4(-14.1)$ & $<0.05$ \\
$P_{\text {plat }}\left(\mathrm{CmH}_{2} \mathrm{O}\right)$ & $30.6 \pm 4.6$ & $27.7 \pm 4.1$ & $-2.9(-9.5)$ & $<0.05$ \\
$\Delta P\left(\mathrm{cmH}_{2} \mathrm{O}\right)$ & $18.3 \pm 4.3$ & $15.6 \pm 3.9$ & $-2.7(-14.8)$ & $<0.05$ \\
$\mathrm{PaO}_{2}(\mathrm{mmHg})$ & $91.8 \pm 23.8$ & $84.4 \pm 18.7$ & $-7.4(-8.1)$ & $<0.05$ \\
$P / F(\mathrm{mmHg})$ & $164 \pm 38$ & $151 \pm 35$ & $-13(-7.9)$ & $<0.05$ \\
\hline
\end{tabular}

$V_{\mathrm{T}}$ tidal volume; $P B W$ predicted body weight; $R M V$ respiratory minute volume; $P_{\text {plat }}$ plateau pressure; $\triangle P$ driving pressure; $\mathrm{PaO}_{2}$ arterial $\mathrm{O}_{2}$ partial pressure; $P / F$ oxygenation index

\section{Discussion}

Using a standardized protocol of ventilation based on current ARDS Network recommendations, we were able to demonstrate that the investigated combination therapy was able to ameliorate respiratory acidosis and effectively reduce the invasiveness of mechanical ventilation in hypercapnic critically ill patients while providing efficient renal replacement therapy and exhibiting a positive effect on hemodynamics in terms of vasopressor requirements. While combinations of $\mathrm{ECCO}_{2} \mathrm{R}$ and CRRT have previously been reported, our study provides the first description of a certified and labeled combination therapy on a commercially available organ support platform. The system was able to eliminate $\mathrm{CO}_{2}$ at a rate between 40 and $50 \mathrm{ml} / \mathrm{min}$, thereby reducing arterial $\mathrm{PCO}_{2}$ significantly by about $10 \%$. The additional integration of a
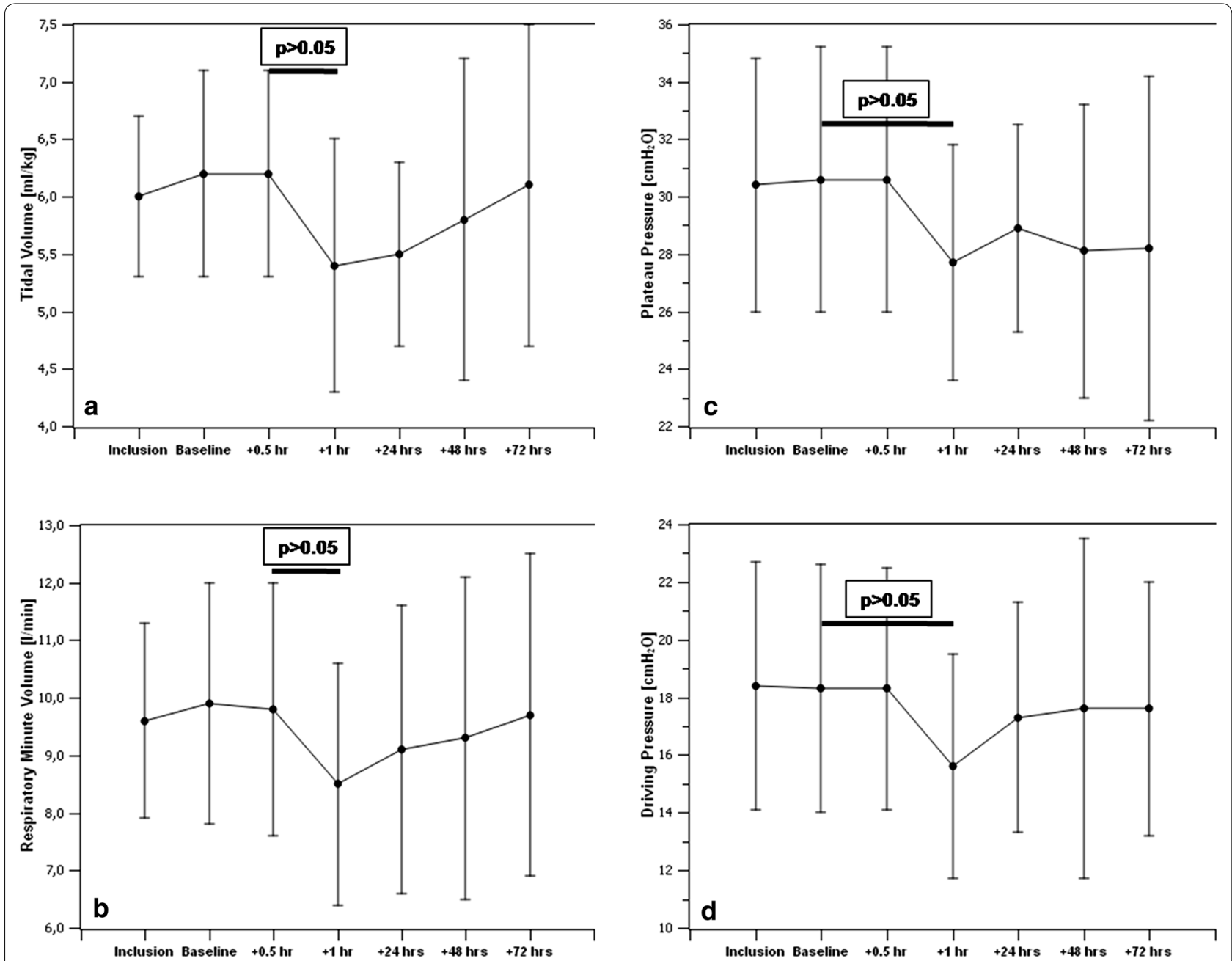

Fig. 3 Changes in ventilation under $\mathrm{ECCO}_{2} \mathrm{R}$ over the study period showing a significant decrease in tidal volumes per predicted body weight (a) and respiratory minute ventilation (b) compared to baseline, corresponding to a significant decrease in plateau (c) and driving pressures (d) 
membrane lung into a renal replacement circuit has first been described by Forster et al. [32], who were able to show a reduction in acidosis and decreased vasopressor requirements in ten hypercapnic patients. This concept was taken one step further by Allardet-Servent et al. [33], who were able to realize an ultra-protective ventilation strategy in 11 patients with ARDS using a similar combination. In both of these studies, membrane lungs with surfaces of about $0.7 \mathrm{~m}^{2}$ were used, which resulted in a higher $\mathrm{CO}_{2}$ removal rate and more pronounced correction of acidosis compared to our system, which incorporated a significantly smaller membrane lung $\left(0.32 \mathrm{~m}^{2}\right)$. As has recently been shown by Karagiannidis et al. [35], in low-flow $\mathrm{ECCO}_{2} \mathrm{R}$ the effectiveness of $\mathrm{CO}_{2}$ extraction is mainly a function of the membrane size. Whereas smaller membrane lungs may have advantages with regard to costs and likelihood of clotting, membrane size must be considered the most important limiting factor of the presented system. Another factor pertaining to combinations of $\mathrm{ECCO}_{2} \mathrm{R}$ and CRRT is the relative position of membrane lung and hemofilter, which may affect $\mathrm{CO}_{2}$ removal. In [33], the incorporation of the membrane lung downstream of the hemofilter was significantly less effective than in an upstream position. In our study, the $\mathrm{CO}_{2}$ removal rate of the combined system was about $5 \%$ lower than the elimination rate of the membrane lung alone, hinting at the same effect. We suggest that the substitution of bicarbonate-rich replacement fluids as a consequence of renal replacement therapy leads to an increase in the $\mathrm{CO}_{2}$ content of extracorporeal blood, thereby counteracting the overall effectiveness of $\mathrm{CO}_{2}$ removal by "loading" the blood with $\mathrm{CO}_{2}$. It would be interesting to investigate whether the use of citrate-based solutions which could also provide effective anticoagulation is associated with a more pronounced $\mathrm{CO}_{2}$ removal effect. Due to the relatively high citrate dosing requirements at the investigated blood flow $(400 \mathrm{ml} / \mathrm{min})$, no such combination is currently available.

Though the resulting drop in $\mathrm{PaCO}_{2}$, as is expected in a low-flow setting, is not sufficient to completely correct respiratory acidosis, implementation of the system still allowed for a significant decrease both in tidal volume $(-0.8 \mathrm{ml} / \mathrm{kg})$ and plateau pressure $\left(-2.9 \mathrm{cmH}_{2} \mathrm{O}\right)$ and in driving pressure $\left(-2.7 \mathrm{cmH}_{2} \mathrm{O}\right)$. Since the study protocol did not require neuromuscular blockade to prevent spontaneous breathing and consequently only a quarter of the patients received neuromuscular blocking agents at some point during the study, there was considerable heterogeneity in response to plateau pressure reduction following implementation of $\mathrm{ECCO}_{2} \mathrm{R}$ with some patients counteracting the decreased inspiratory pressures by actively increasing spontaneous breathing efforts, thus mitigating the effect on tidal volume reduction.
In a recent study on the efficacy and safety of low-flow $\mathrm{ECCO}_{2} \mathrm{R}$ using the same platform in patients without renal failure, a more pronounced reduction in tidal volume and plateau pressure was reported [36]. In that study, all patients were paralyzed, making tidal volume reductions more easy to achieve. Also, the severity of illness was significantly different with a mean SOFA score of 9 as compared to 14 in our study. It is important to note that patients with combined respiratory and renal failure may constitute a different target group for $\mathrm{ECCO}_{2} \mathrm{R}$ than patients with isolated respiratory failure. In established multi-organ failure with often severe concomitant metabolic acidosis, there is typically an indication for renal replacement therapy, making the integration of an additional gas exchanger in the circuit much less invasive since vascular access is already in place. Our data show that combining $\mathrm{ECCO}_{2} \mathrm{R}$ with CRRT in the setting multiorgan failure, while being less effective than stand-alone therapies, can still significantly enhance lung protection and may therefore have beneficial effects. In contrast to [36], this effect can be achieved without further raising $\mathrm{PaCO}_{2}$, thus providing much better control of $\mathrm{pH}$. Interestingly, while the additional surface of the hemofilter might be expected to activate coagulation, incidence of circuit clotting was much lower in the combination therapy than in the stand-alone procedure.

As it has been concluded by Gattinoni et al., ventilator-associated lung injury essentially results from the application of mechanical power to the lungs in order to actively eliminate $\mathrm{CO}_{2}$ from the circulation $[37,38]$. The components of this mechanical power are tidal volume, driving pressure, PEEP, flow and respiratory rate. Any additional $\mathrm{CO}_{2}$ elimination is therefore capable of reducing the power applied to the lungs and consequently should attenuate ventilator-associated lung injury. This is mirrored in our study by significantly decreased tidal volumes and driving pressures. Although this rationale may seem compelling and comparable strategies have been able to show reduced systemic and pulmonary inflammation in experimental $[39,40]$ as well as in clinical ARDS $[14,27]$, to date it has not been demonstrated that ultraprotective ventilation strategies per se can improve clinically relevant patient outcomes.

Although partial extracorporeal $\mathrm{CO}_{2}$ elimination must therefore still be regarded as experimental at this juncture, due to its easy implementation and management, the combination of low-flow $\mathrm{ECCO}_{2} \mathrm{R}$ and CRRT nevertheless constitutes a safe and effective add-on therapy for ventilated patients with renal failure. Since the procedure runs on an established renal replacement platform and therefore only requires integration of a small membrane lung as well as a moderate increase in blood flow without need for specialized vascular access, the potential for 
complications seems low. Under systemic anticoagulation, the combined system exhibited reasonable circuit lifetimes and we observed no procedure-related bleeding or other relevant adverse events. This is in marked contrast to ECMO or even mid-flow $\mathrm{ECCO}_{2} \mathrm{R}$ therapies where higher blood flows can provide total $\mathrm{CO}_{2}$ removal but require large-bore and often multiple vascular access which is associated with significant bleeding risk and other local as well as systemic complications [12-14, $16]$. We therefore conclude that combined $\mathrm{ECCO}_{2} \mathrm{R}$ and CRRT with the investigated system is a feasible and safe approach. However, due to the limited running time of the hemofilter for renal replacement, the system has to be discarded after $72 \mathrm{~h}$, leading potentially to higher costs in prolonged treatments.

Our study has several limitations. In order to keep interference with local practice standards at the three centers at a minimum, no explicit ventilation strategy other than compliance with ARDS Network recommendations was stipulated. After the initial data collections, ventilation strategy was left to the discretion of the treating physician leading to considerable heterogeneity among the study population. With a growing number of spontaneously breathing patients over the study period, the effect of $\mathrm{ECCO}_{2} \mathrm{R}$ on ventilation is blurred to a considerable degree. Since neuromuscular blockade was not required, even the initial data collections may be significantly influenced by spontaneous breathing efforts. As expected in combined lung and renal failure, metabolic acidosis significantly contributes to overall acid base status. Consequently, in a number of patients, while $\mathrm{ECCO}_{2} \mathrm{R}$ led to a significant drop in $\mathrm{PaCO}_{2}$, marked overall acidosis remained, preventing a reduction in ventilator settings by the treating physician. We therefore cannot exclude that the overall effect on ventilation is confounded to some degree in this study. Furthermore, the study included only patients who already exhibited severe hypercapnia. Our data therefore allow no statement on the efficiency of the system in a normocapnic or only mildly hypercapnic environment. Due to the limited running time of the system $(72 \mathrm{~h}$ ), we also cannot provide data on long-term clinical effects.

\section{Conclusions}

In this study, we present the first description of a combination of extracorporeal $\mathrm{CO}_{2}$ removal and renal replacement therapy on a commercially available organ support platform in mechanically ventilated hypercapnic patients with renal failure. The investigated combination therapy was able to ameliorate hypercapnic acidosis and allow for a decrease in ventilation pressures while providing adequate renal replacement therapy. The system was easy to implement and manage; no severe procedure-related adverse events were observed. Whether strategies aiming at correcting hypercapnia and/or providing ultra-protective ventilation are beneficial for patients with combined lung and renal failure in terms of outcome remains to be demonstrated in future investigations.

\begin{abstract}
Abbreviations
$\mathrm{CO}_{2}$ : carbon dioxide; $\mathrm{ARDS}$ : acute respiratory distress syndrome; $\mathrm{ECCO}_{2} \mathrm{R}$ : extracorporeal $\mathrm{CO}_{2}$ removal; $\mathrm{PaCO}_{2}$ : arterial $\mathrm{CO}_{2}$ partial pressure; $\mathrm{PBW}$ : predicted body weight; ECMO: extracorporeal membrane oxygenation; pECLA: pumpless extracorporeal lung assist; CRRT: continuous renal replacement therapy; aPTT: activated partial thromboplastin time; CVVHF: continuous veno-venous hemofiltration; RASS: Richmond agitation and sedation scale; $P_{\text {plat }}$ : plateau pressure; BMI: body mass index; SAPS: Simplified Acute Physiology Score; SOFA: Sequential Organ Failure Assessment; COPD: chronic obstructive pulmonary disease; CIHD: chronic intermittent hemodialysis; NMBA: neuromuscular blocking agent; $\mathrm{SD}$ : standard deviation; $\mathrm{HCO}_{3}$ : bicarbonate; $\mathrm{CaCO}_{2}$ : arterial $\mathrm{CO}_{2}$ content; SBE: standard base excess; $\mathrm{SaO}_{2}$ : arterial oxygen saturation; P/F: oxygenation index; $V_{T}$ : tidal volume; RR: respiratory rate; RMV: respiratory minute ventilation; PEEP: positive end-expiratory pressure; $\triangle P$ : driving pressure; $C_{\text {dyn }}$ : dynamical compliance; $\mathrm{HR}$ : heart rate; MAP: mean arterial pressure; $\mathrm{PCO}_{2}: \mathrm{CO}_{2}$ partial pressure; $\mathrm{PaO}_{2}$ : arterial $\mathrm{O}_{2}$ partial pressure; $\triangle \mathrm{PO}_{2}: \mathrm{O}_{2}$ partial pressure difference; RBC: red blood cells.
\end{abstract}

\section{Authors' contributions}

JN, SK and SJ were involved in study protocol and ethics. JN, DW, SL and HM collected the data. JN and SJ prepared the data/statistics. JN, SK, HM and SJ wrote the manuscript. All authors read and approved the final manuscript.

\section{Author details}

${ }^{1}$ Medical Intensive Care, Department of Cardiology, Klinikum Nuremberg, Paracelsus Medical University, Nuremberg, Germany. ${ }^{2}$ Department of Intensive Care Medicine, University Medical Center Hamburg-Eppendorf, Hamburg, Germany. ${ }^{3}$ Department of Anesthesia, Intensive Care Medicine and Pain Therapy, University Hospital Frankfurt, Frankfurt, Germany.

\section{Acknowledgements}

Not applicable.

\section{Competing interests}

JN received honoraria from Baxter Healthcare Corporation, USA, for oral presentations. SJ received honoraria from Baxter Healthcare Corporation, USA, for oral presentations and is a member of a Medical Advisory Board organized by Baxter. DW received honoraria from Baxter Healthcare Corporation, USA, for oral presentations and is a member of a Medical Advisory Board organized by Baxter. SK is currently on the Medical Advisory Boards of Baxter, Fresenius and Xenios. HM received honoraria from Fresenius Medical Care, Germany, and SALVIA, Germany, for oral presentations.

\section{Availability of data and materials}

The datasets generated and analyzed during this study are available from the corresponding author on reasonable request.

\section{Consent for publication}

Not applicable.

\section{Ethics Approval and consent to participate}

The study was approved by the ethics committee of the Friedrich-Alexander University Erlangen-Nuremberg, Germany, under the reference number 213_14 B. The study has been performed in accordance with the ethical standards laid down in the 1964 Declaration of Helsinki and its later amendments. 


\section{Funding}

The study was funded by a grant of Baxter Healthcare Corporation, USA. The funding body was not involved in the design of the study or the collection, analysis and interpretation of the data or in the writing of the manuscript.

\section{Publisher's Note}

Springer Nature remains neutral with regard to jurisdictional claims in publishedmaps and institutional affiliations.

Received: 2 August 2018 Accepted: 2 January 2019

Published online: 07 January 2019

\section{References}

1. Acute Respiratory Distress Syndrome Network, Brower RG, Matthay MA, Morris A, Schoenfeld D, Thompson BT, Wheeler A. Ventilation with lower tidal volumes as compared with traditional tidal volumes for acute lung injury and the acute respiratory distress syndrome. N Engl J Med. 2000;342(18):1301-8

2. Amato MB, Barbas CS, Medeiros DM, Magaldi RB, Schettino GP, LorenziFilho G, Kairalla RA, Deheinzelin D, Munoz C, Oliveira R, Takagaki TY, Carvalho CR. Effect of a protective-ventilation strategy on mortality in the acute respiratory distress syndrome. N Engl J Med. 1998;338(6):347-54.

3. ARDS Definition Task Force, Ranieri VM, Rubenfeld GD, Thompson BT, Ferguson ND, Caldwell E, Fan E, Camporota L, Slutsky AS. Acute respiratory distress syndrome: the Berlin definition. JAMA. 2012;307(23):2526-33. https://doi.org/10.1001/jama.2012.5669.

4. Slutsky AS, Ranieri VM. Ventilator-induced lung injury. N Engl J Med. 2013;369(22):2126-36. https://doi.org/10.1056/NEJMra1208707.

5. Terragni PP, Rosboch G, Tealdi A, Corno E, Menaldo E, Davini O, Gandini G, Herrmann P, Mascia L, Quintel M, Slutsky AS, Gattinoni L, Ranieri VM. Tidal hyperinflation during low tidal volume ventilation in acute respiratory distress syndrome. Am J Respir Crit Care Med. 2007;175(2):160-6.

6. Curley G, Hayes M, Laffey JG. Can 'permissive' hypercapnia modulate the severity of sepsis-induced ALI/ARDS? Crit Care. 2011;15(2):212. https:// doi.org/10.1186/cc9994.

7. Ismaiel NM, Henzler D. Effects of hypercapnia and hypercapnic acidosis on attenuation of ventilator-associated lung injury. Minerva Anestesiol. 2011;77(7):723-33.

8. Vadász I, Hubmayr RD, Nin N, Sporn PH, Sznajder Jl. Hypercapnia: a nonpermissive environment for the lung. Am J Respir Cell Mol Biol. 2012;46(4):417-21. https://doi.org/10.1165/rcmb.2011-0395ps.

9. Curley G, Contreras MM, Nichol AD, Higgins BD, Laffey JG. Hypercapnia and acidosis in sepsis: a double-edged sword? Anesthesiology. 2010;112(2):462-72. https://doi.org/10.1097/ALN.0b013e3181ca361f.

10. Nin N, Muriel A, Peñuelas O, Brochard L, Lorente JA, Ferguson ND, Raymondos K, Ríos F, Violi DA, Thille AW, González M, Villagomez AJ, Hurtado J, Davies AR, Du B, Maggiore SM, Soto L, D’Empaire G, Matamis D, Abroug F, Moreno RP, Soares MA, Arabi Y, Sandi F, Jibaja M, Amin P, Koh Y, Kuiper MA, Bülow HH, Zeggwagh AA, Anzueto A, Sznajder JI, Esteban A, VENTILA Group. Severe hypercapnia and outcome of mechanically ventilated patients with moderate or severe acute respiratory distress syndrome. Intensive Care Med. 2017;43(2):200-8. https://doi.org/10.1007/s0013 4-016-4611-1.

11. Tiruvoipati R, Pilcher D, Buscher H, Botha J, Bailey M. Effects of hypercapnia and hypercapnic acidosis on hospital mortality in mechanically ventilated patients. Crit Care Med. 2017;45(7):e649-56. https://doi. org/10.1097/CCM.0000000000002332.

12. Kreppein $U$, Litterst $P$, Westhoff $M$. Hypercapnic respiratory failure. Pathophysiology, indications for mechanical ventilation and management. Med Klin Intensivmed Notfmed. 2016;111(3):196-201. https://doi org/10.1007/s00063-016-0143-2.

13. Bein T, Zimmermann M, Hergeth $K$, Ramming M, Rupprecht $L$, Schlitt HJ, Slutsky AS. Pumpless extracorporeal removal of carbon dioxide combined with ventilation using low tidal volume and high positive end-expiratory pressure in a patient with severe acute respiratory distress syndrome. Anaesthesia. 2009;64(2):195-8. https://doi.org/10.111 1/j.1365-2044.2008.05735.x.
14. Bein T, Weber-Carstens $S$, Goldmann A, Müller T, Staudinger T, Brederlau J, Muellenbach R, Dembinski R, Graf BM, Wewalka M, Philipp A, Wernecke $K D$, Lubnow M, Slutsky AS. Lower tidal volume strategy $(\approx 3 \mathrm{ml} / \mathrm{kg})$ combined with extracorporeal $\mathrm{CO} 2$ removal versus 'conventional' protective ventilation $(6 \mathrm{ml} / \mathrm{kg})$ in severe ARDS: the prospective randomized Xtravent-study. Intensive Care Med. 2013;39(5):847-56. https://doi. org/10.1007/s00134-012-2787-6.

15. Gattinoni L, Kolobow T, Tomlinson T, White D, Pierce J. Control of intermittent positive pressure breathing (IPPB) by extracorporeal removal of carbon dioxide. Br J Anaesth. 1978;50(8):753-8.

16. Braune $S$, Sieweke A, Jarczak D, Kluge S. Extracorporeal lung support. Med Klin Intensivmed Notfmed. 2017;112(5):426-36. https://doi.org/10.1007/ s00063-017-0304-y.

17. Mosier JM, Kelsey M, Raz Y, Gunnerson KJ, Meyer R, Hypes CD, Malo J, Whitmore SP, Spaite DW. Extracorporeal membrane oxygenation (ECMO) for critically ill adults in the emergency department: history, current applications, and future directions. Crit Care. 2015;17(19):431. https://doi. org/10.1186/s13054-015-1155-7.

18. Peek GJ, Mugford M, Tiruvoipati R, Wilson A, Allen E, Thalanany MM, Hibbert CL, Truesdale A, Clemens F, Cooper N, Firmin RK, Elbourne D. CESAR trial collaboration. Efficacy and economic assessment of conventional ventilatory support versus extracorporeal membrane oxygenation for severe adult respiratory failure (CESAR): a multicentre randomised controlled trial. Lancet. 2009;374(9698):1351-63. https://doi.org/10.1016/ s0140-6736(09)61069-2.

19. Staudinger T. Extracorporeal membrane oxygenation: system selection, (contra)indications, and management. Med Klin Intensivmed Notfmed. 2017;112(4):295-302. https://doi.org/10.1007/s00063-017-0279-8.

20. Millar JE, Fanning JP, McDonald Cl, McAuley DF, Fraser JF. The inflammatory response to extracorporeal membrane oxygenation (ECMO): a review of the pathophysiology. Crit Care. 2016;20(1):387.

21. Murphy DA, Hockings LE, Andrews RK, Aubron C, Gardiner EE, Pellegrino VA, Davis AK. Extracorporeal membrane oxygenation-hemostatic complications. Transfus Med Rev. 2015;29(2):90-101. https://doi.org/10.1016/j. tmrv.2014.12.001

22. Zangrillo A, Landoni G, Biondi-Zoccai G, Greco M, Greco T, Frati G, Patroniti N, Antonelli M, Pesenti A, Pappalardo F. A meta-analysis of complications and mortality of extracorporeal membrane oxygenation. Crit Care Resusc. 2013;15(3):172-8.

23. Braune $S$, Sieweke A, Brettner F, Staudinger T, Joannidis M, Verbrugge $S$, Frings D, Nierhaus A, Wegscheider K, Kluge S. The feasibility and safety of extracorporeal carbon dioxide removal to avoid intubation in patients with COPD unresponsive to noninvasive ventilation for acute hypercapnic respiratory failure (ECLAIR study): multicentre case-control study. Intensive Care Med. 2016;42(9):1437-44. https://doi.org/10.1007/s0013 4-016-4452-y.

24. Hermann A, Riss K, Schellongowski P, Bojic A, Wohlfarth P, Robak O, Sperr WR, Staudinger T. A novel pump-driven veno-venous gas exchange system during extracorporeal $\mathrm{CO}_{2}$-removal. Intensive Care Med. 2015;41(10):1773-80. https://doi.org/10.1007/s00134-015-3957-0.

25. Livigni S, Maio M, Ferretti E, Longobardo A, Potenza R, Rivalta L, Selvaggi P, Vergano M, Bertolini G. Efficacy and safety of a low-flow veno-venous carbon dioxide removal device: results of an experimental study in adult sheep. Crit Care. 2006;10(5):R151.

26. Batchinsky Al, Jordan BS, Regn D, Necsoiu C, Federspiel WJ, Morris MJ, Cancio LC. Respiratory dialysis: reduction in dependence on mechanical ventilation by venovenous extracorporeal $\mathrm{CO}_{2}$ removal. Crit Care Med. 2011;39(6):1382-7. https://doi.org/10.1097/CCM.0b013e31820eda45.

27. Terragni PP, Del Sorbo L, Mascia L, Urbino R, Martin EL, Birocco A, Faggiano C, Quintel M, Gattinoni L, Ranieri VM. Tidal volume lower than $6 \mathrm{ml} / \mathrm{kg}$ enhances lung protection: role of extracorporeal carbon dioxide removal. Anesthesiology. 2009;111(4):826-35. https://doi.org/10.1097/ ALN.0b013e3181b764d2.

28. Esteban A, Alía I, Gordo F, de Pablo R, Suarez J, González G, Blanco J. Prospective randomized trial comparing pressure-controlled ventilation and volume-controlled ventilation in ARDS, For the Spanish Lung Failure Collaborative Group. Chest. 2000;117(6):1690-6.

29. Liu KD, Matthay MA. Advances in critical care for the nephrologist: acute lung injury/ARDS. Clin J Am Soc Nephrol. 2008;3(2):578-86. https://doi. org/10.2215/cjn.01630407. 
30. Faubel $\mathrm{S}$, Edelstein CL. Mechanisms and mediators of lung injury after acute kidney injury. Nat Rev Nephrol. 2016;12(1):48-60. https://doi. org/10.1038/nrneph.2015.158.

31. John S, Willam C. Lung and kidney failure. Pathogenesis, interactions, and therapy. Med Klin Intensivmed Notfmed. 2015;110(6):452-8. https://doi. org/10.1007/s00063-014-0404-x.

32. Forster C, Schriewer J, John S, Eckardt KU, Willam C. Low-flow $\mathrm{CO}_{2}$ removal integrated into a renal-replacement circuit can reduce acidosis and decrease vasopressor requirements. Crit Care. 2013;17(4):R154. https ://doi.org/10.1186/cc12833.

33. Allardet-Servent J, Castanier M, Signouret T, Soundaravelou R, Lepidi A, Seghboyan JM. Safety and efficacy of combined extracorporeal $\mathrm{CO}_{2}$ removal and renal replacement therapy in patients with acute respiratory distress syndrome and acute kidney injury: the pulmonary and renal support in acute respiratory distress syndrome study. Crit Care Med. 2015;43(12):2570-81. https://doi.org/10.1097/CCM.0000000000001296.

34. Godet T, Combes A, Zogheib E, Jabaudon M, Futier E, Slutsky AS, Constantin JM. Novel $\mathrm{CO}_{2}$ removal device driven by a renal-replacement system without hemofilter. A first step experimental validation. Anaesth Crit Care Pain Med. 2015;34(3):135-40. https://doi.org/10.1016/j.accpm 2014.08.006

35. Karagiannidis C, Strassmann S, Brodie D, Ritter P, Larsson A, Borchardt R, Windisch W. Impact of membrane lung surface area and blood flow on extracorporeal $\mathrm{CO}(2)$ removal during severe respiratory acidosis. Intensive Care Med Exp. 2017;5(1):34. https://doi.org/10.1186/s40635-017-0147-0.

36. Schmidt M, Jaber S, Zogheib E, Godet T, Capellier G, Combes A. Feasibility and safety of low-flow extracorporeal $\mathrm{CO}(2)$ removal managed with a renal replacement platform to enhance lung-protective ventilation of patients with mild-to-moderate ARDS. Crit Care. 2018;22(1):122. https:// doi.org/10.1186/s13054-018-2038-5.

37. Gattinoni L, Tonetti T, Cressoni M, Cadringher P, Herrmann $P$, Moerer $O$ Protti A, Gotti M, Chiurazzi C, Carlesso E, Chiumello D, Quintel M. Ventilator-related causes of lung injury: the mechanical power. Intensive Care Med. 2016:42(10):1567-75. https://doi.org/10.1007/s00134-016-4505-2.

38. Gattinoni L, Marini JJ, Collino F, Maiolo G, Rapetti F, Tonetti T, Vasques F, Quintel M. The future of mechanical ventilation: lessons from the present and the past. Crit Care. 2017;21(1):183. https://doi.org/10.1186/s1305 4-017-1750-x.

39. Grasso S, Stripoli T, Mazzone P, Pezzuto M, Lacitignola L, Centonze P, Guarracino A, Esposito C, Herrmann P, Quintel M, Trerotoli P, Bruno F, Crovace A, Staffieri F. Low respiratory rate plus minimally invasive extracorporeal $\mathrm{CO}_{2}$ removal decreases systemic and pulmonary inflammatory mediators in experimental acute respiratory distress syndrome. Crit Care Med. 2014;42(6):e451-60. https://doi.org/10.1097/CCM.0000000000000312.

40. Güldner A, Kiss T, Bluth T, Uhlig C, Braune A, Carvalho N, Quast T, Rentzsch I, Huhle R, Spieth P, Richter T, Saddy F, Rocco PR, Kasper M, Koch T, Pelosi P, de Abreu MG. Effects of ultraprotective ventilation, extracorporeal carbon dioxide removal, and spontaneous breathing on lung morphofunction and inflammation in experimental severe acute respiratory distress syndrome. Anesthesiology. 2015;122(3):631-46. https://doi.org/10.1097/ ALN.0000000000000504.

\section{Submit your manuscript to a SpringerOpen ${ }^{\circ}$ journal and benefit from:}

- Convenient online submission

- Rigorous peer review

- Open access: articles freely available online

- High visibility within the field

- Retaining the copyright to your article

Submit your next manuscript at $\boldsymbol{\nabla}$ springeropen.com 